Supporting Information

\title{
Model for the Prediction of the Lifetime and Energy Yield of Methyl Ammonium Lead Iodide Perovskite Solar Cells at Elevated Temperatures
}

João P. Bastos, ${ }^{* \dagger \ddagger}$ Griet Uytterhoeven, ${ }^{\dagger}$ Weiming Qiu, ${ }^{\dagger}$ Ulrich W. Paetzold, ${ }^{\dagger \perp}$ David Cheyns, ${ }^{\dagger}$ Supriya Surana, ${ }^{\dagger \S}$ Javier Rivas," Manoj Jaysankar, ${ }^{\dagger \neq ~ W e n y a ~ S o n g, ~}{ }^{\dagger \neq}$ Tom Aernouts, ${ }^{\dagger}$ Jef Poortmans $^{\dagger \ddagger \#}$ and Robert Gehlhaar ${ }^{\dagger}$

${ }^{\dagger}$ Imec - part of Solliance, Kapeldreef 75, 3001 Heverlee, Belgium

‡ Department of Electrical Engineering, Katholieke Universiteit Leuven, Kasteelpark Arenberg 10, B-3001, Leuven, Belgium

${ }^{\perp}$ Institute of Microstructure Technology, Karlsruhe Institute of Technology, Hermann-von-Helmholtz-Platz 1, 76344 Eggenstein-Leopoldshafen, Karlsruhe, Germany

$\S$ Department Physics, Katholieke Universiteit Leuven, Celestijnenlaan 200d, B-3001, Leuven, Belgium

" Faculty of Science, University La Laguna, 38200 San Cristóbal de La Laguna, Spain

\# Institute for Materials Research \& IMEC-associated lab IMOMEC, Hasselt University, Wetenschapspark 1, B3590 Diepenbeek, Belgium

Corresponding Author

* joao.bastos@imec.be. 


\section{Stability at Elevated Temperatures with Different Hole Transport Layers}

Table S-1 - Device characteristics of devices with PTAA and spiro-MeOTAD as HTL. The results are the average of 9 cells and the standard deviation is also presented.

\begin{tabular}{|c|c|c|c|c|}
\hline HTL & $\begin{array}{c}J_{\text {sc }} \\
{\left[\mathrm{mA} \mathrm{cm}^{-2}\right]}\end{array}$ & $\begin{array}{c}V_{\text {oc }} \\
{[\mathrm{mV}]}\end{array}$ & $\begin{array}{c}\text { FF } \\
{[\%]}\end{array}$ & $\begin{array}{c}\text { PCE } \\
{[\%]}\end{array}$ \\
\hline PTAA & $20.7 \pm 1.1$ & $870 \pm 30$ & $66.9 \pm 3.2$ & $12.1 \pm 1.1$ \\
\hline spiro-MeOTAD & $20.4 \pm 1.1$ & $890 \pm 10$ & $69.1 \pm 2.5$ & $12.5 \pm 0.7$ \\
\hline
\end{tabular}
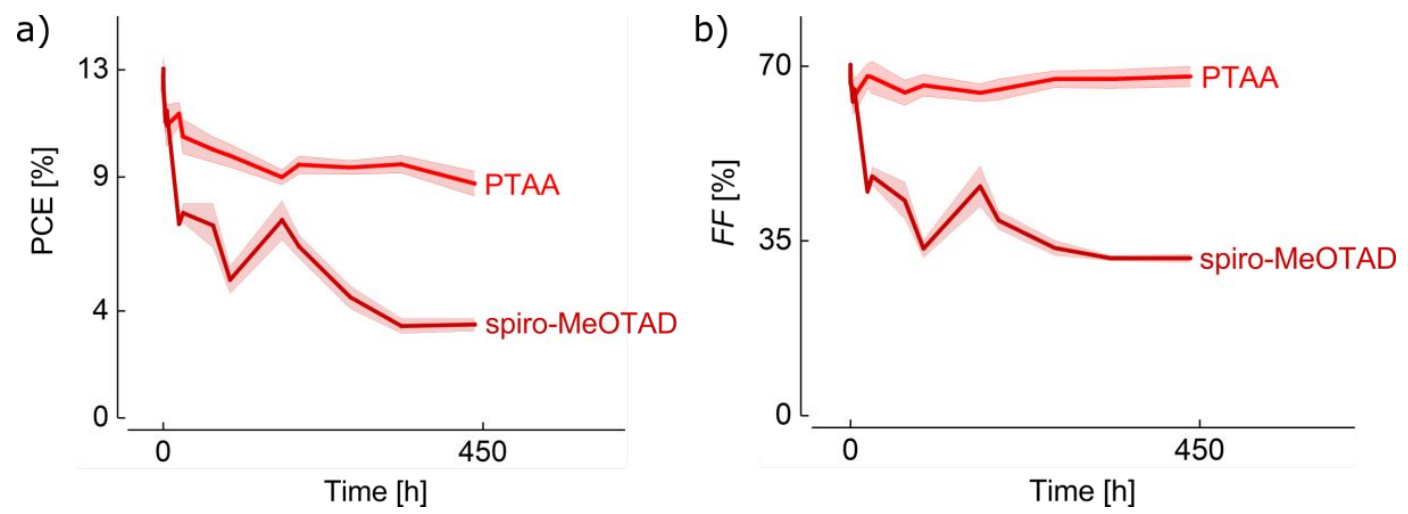

Figure S-1 - Devices with spiro-MeOTAD as HTL have lower thermal stability than devices with PTAA. Evolution of: a) PCE and b) FF, of devices with different HTL stored in N2 at $85^{\circ} \mathrm{C}$ in between measurements.

Table S-2 - Device characteristics of devices with PTAA as HTL.

\begin{tabular}{|c|c|c|c|c|}
\hline & $\begin{array}{c}J_{\text {sc }} \\
{\left[\mathrm{mA} \mathrm{cm}^{-2}\right]}\end{array}$ & $\begin{array}{c}V_{\text {oc }} \\
{[\mathrm{mV}]}\end{array}$ & $\begin{array}{c}\text { FF } \\
{[\%]}\end{array}$ & $\begin{array}{c}\text { PCE } \\
{[\%]}\end{array}$ \\
\hline 78 devices & $20.9 \pm 0.3$ & $790 \pm 20$ & $69.1 \pm 4.1$ & $11.4 \pm 0.9$ \\
\hline
\end{tabular}




\section{Characterization of the Effects of Elevated Temperatures on the Devices}
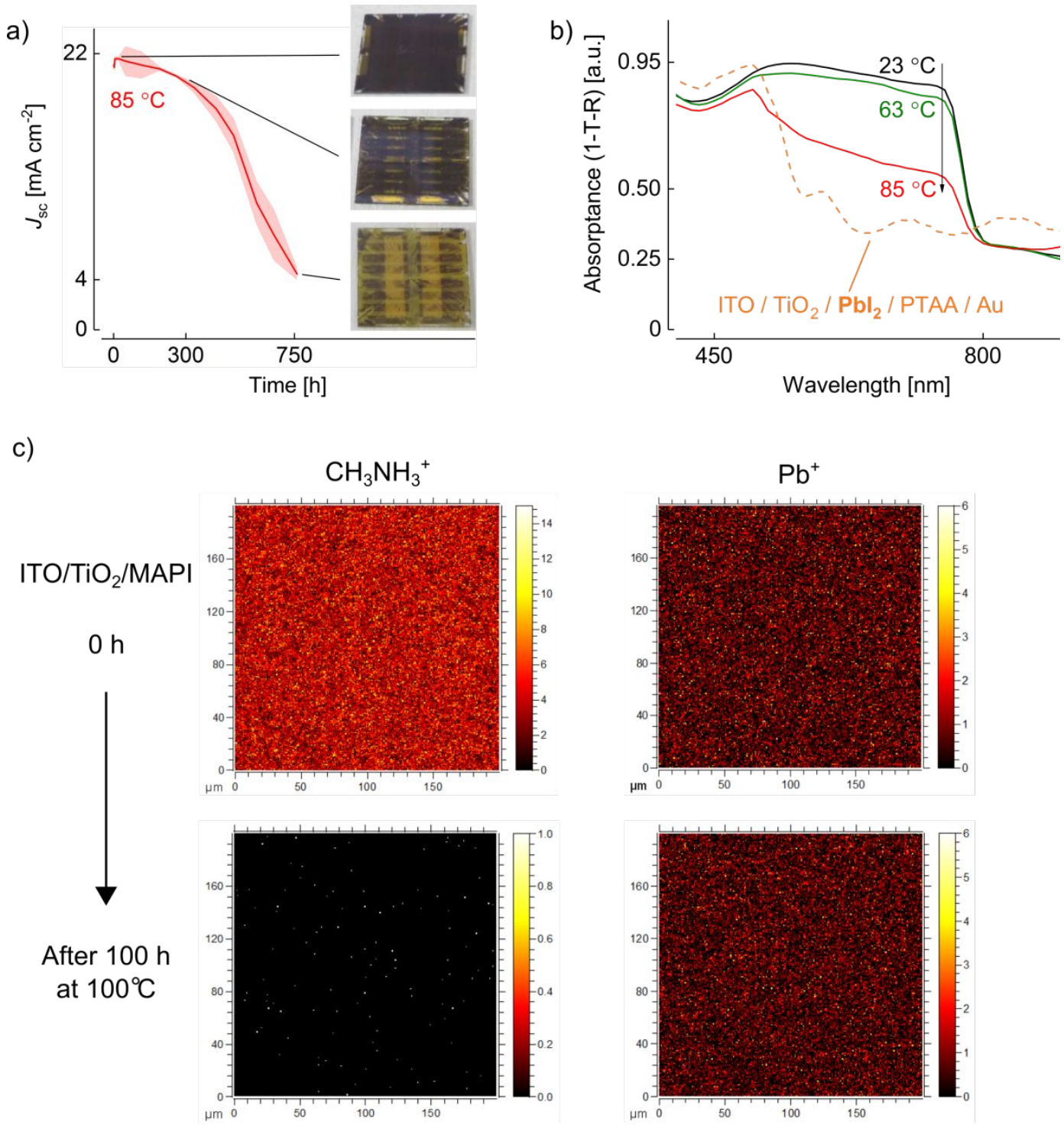

Figure S-2 - Different characterization methods confirm the degradation of MAPI when heated at $85{ }^{\circ} \mathrm{C}$ : a) photos of the same substrate stored at $85^{\circ} \mathrm{C}$ at different times; b) Absorption of devices after testing at different temperatures together and of a device with the structure: $\mathrm{ITO} / \mathrm{TiO}_{2} / \mathrm{PbI}_{2} / \mathrm{PTAA} / \mathrm{Au}$; c) area scan of the composition of the active layer of pristine and degradaded $\mathrm{ITO} / \mathrm{TiO}_{2} / \mathrm{MAPI}$. 


\section{Jsc Reduction}

The $J_{\mathrm{sc}}$ values are corrected for the power fluctuations of the solar simulator, hence the simultaneous variations of $J_{\text {sc }}$ independently of the testing temperature (Figure S3). For the correction, the $J_{\mathrm{sc}}$ values are first normalized, because devices present slightly different initial values. Then, the $J_{\text {sc }}$ values are corrected to the values of the devices stored at $23{ }^{\circ} \mathrm{C}$. Also, there is no need to correct for $\mathrm{PbI}_{2}$ contributions to the $J_{\mathrm{sc}}$, because the devices with $\mathrm{PbI}_{2}$ as active layer (ITO / $\mathrm{TiO}_{2} / \mathrm{PbI}_{2} / \mathrm{PTAA} / \mathrm{Au}$ ) have a current of only $0.01 \mathrm{~mA} \mathrm{~cm}^{-2}$, which is negligible compared with the initial $21 \mathrm{~mA} \mathrm{~cm}^{-2}$ of the devices with MAPI.
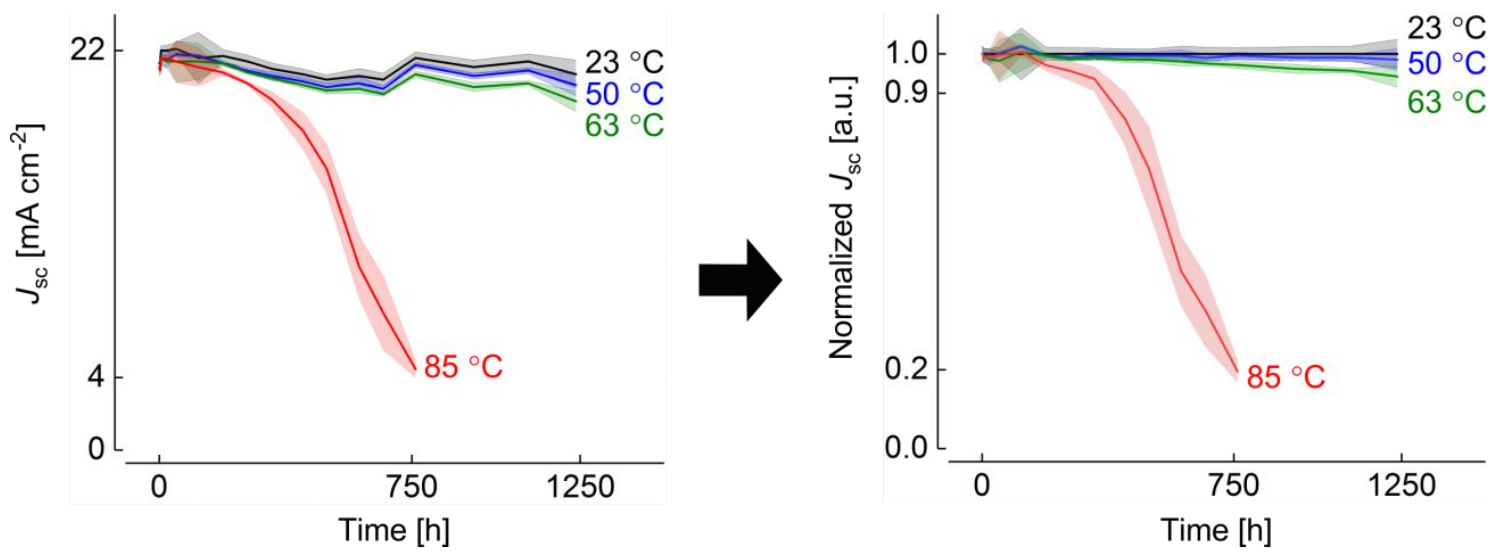

Figure $\mathrm{S}-3$ - Correction of the $\mathrm{J}_{\mathrm{sc}}$ values for the initial value variations and power fluctuations.

a)

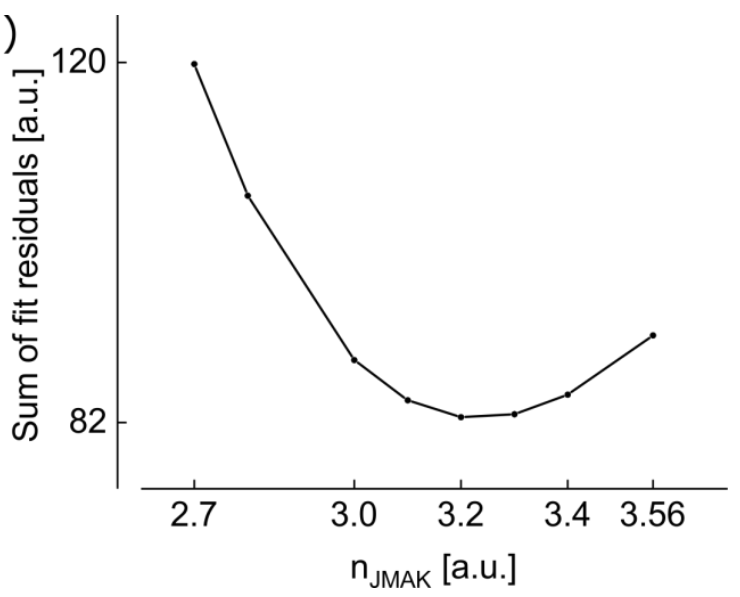

b)

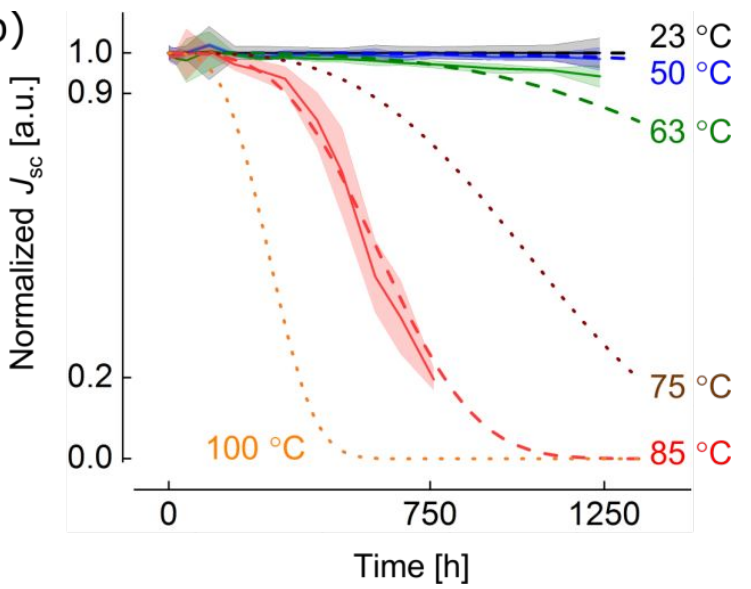

Figure S-4 - Modeling of the $\mathrm{J}_{\mathrm{sc}}$ degradation: a) sum of the residuals from the fits with the JMAK equation for different $\mathrm{n}_{\text {JMAK }}$ b) comparison between the experimental values and the function derived to describe the progression of the $\mathrm{J}_{\mathrm{sc}}$. Dashed lines describe experimental temperatures and dotted lines describe other temperatures. 


\section{Effect of the Temperature Ramp and Activation Energy on Ramped Measurements}

For a given temperature ramp, the temperature at each moment is: $T(t)=T_{0}+d T / d t \times t$, where $T_{0}$ is $20{ }^{\circ} \mathrm{C}$.

The figures below illustrate how the on-set temperature increases with the temperature ramp and $E_{\mathrm{a}}$. Moreover, these calculations demonstrate that no assertions can be made about isothermal testing based on only one ramped temperature measurement.

a)

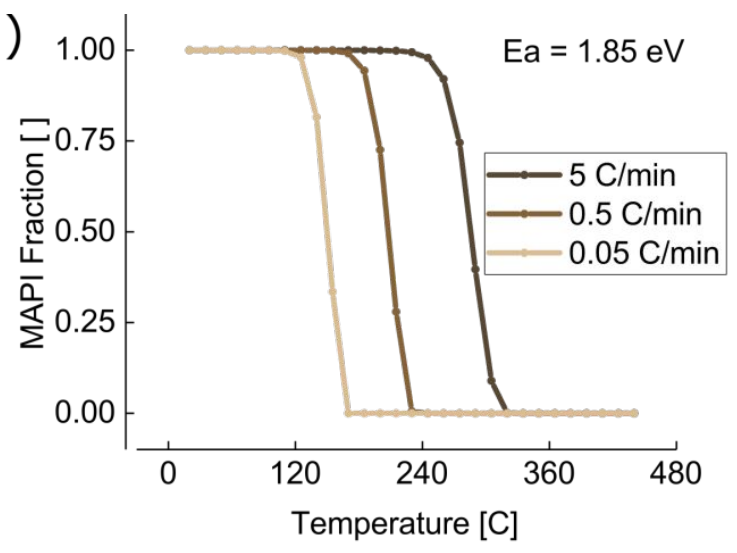

b)

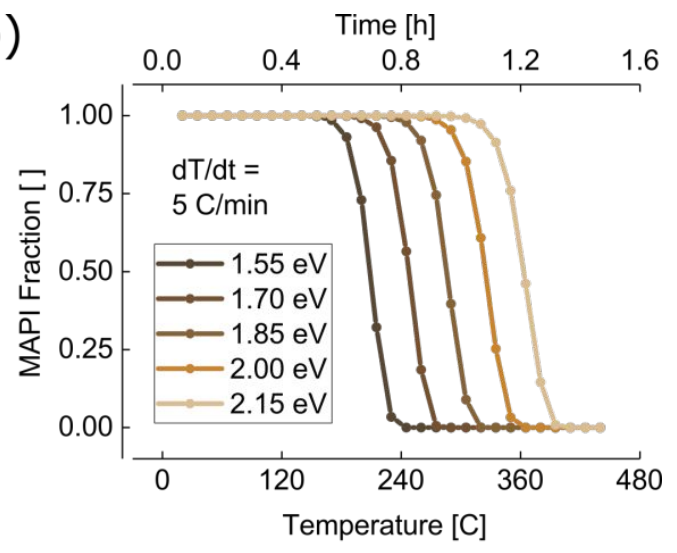

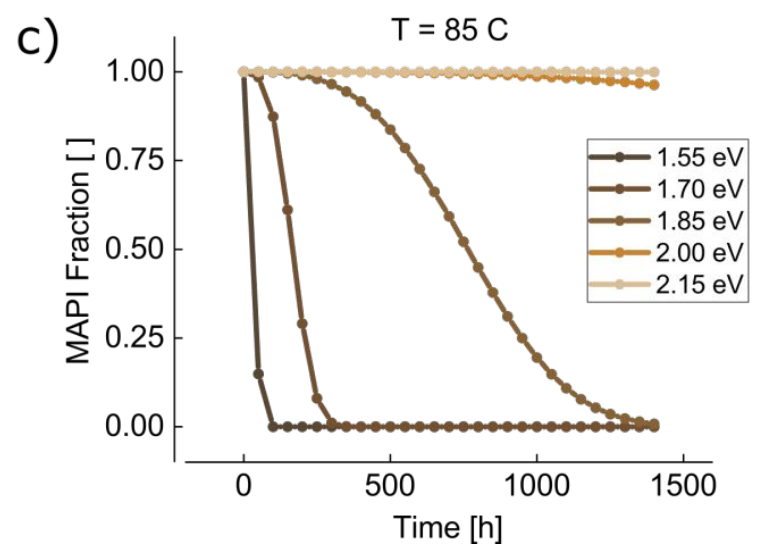

Figure S-5 - Progress of the MAPI content: a) as a function of the temperature ramp for a fixed Ea; b) as a function of Ea with a fixed temperature ramp; c) as function of Ea at $85 \mathrm{C}$.

\section{Simulation of the Jsc reduction}

The 'active volume' results from the overlap of the ITO stripe ( $5 \mathrm{~mm}$ wide), with the Au contact ( $2.5 \mathrm{~mm}$ wide)

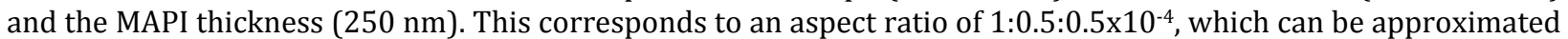
to a 2D array with an aspect ratio of 2:1. Thus, for computational economy, a $100 \times 200$ matrix is chosen for the simulations (Figure S5).

Two nucleation possibilities are considered: either all the nucleation sites are present at $\mathrm{t}=0$ (saturated nucleation), or the nuclei are formed at a constant rate (Figure S5). Moreover, the nuclei are considered to form randomly in non-degraded locations (homogeneous nucleation) or form only in the center ('bulk' nucleation), or only at the edges ('edge' nucleation) of the active area (Figure S5). In the simulation, the nuclei are circular and their radius increases linearly with time, as observed for most solid-state reactions and as assumed in the derivation of the JMAK equation..$^{18}$ Moreover, the degraded areas that overlap are only counted once. Different amounts of nuclei $(2,5,10$ and 20) are considered and the time is defined as an evenly spaced vector from 0 to 100. The final curve of the $\mathrm{PbI}_{2}$ nucleation and growth, $\varphi(\mathrm{t})$, is the average from 100 simulations. For an easier comparison with the reduction of $J_{\mathrm{sc}}$, the remaining MAPI amount is calculated from the amount of $\mathrm{PbI}_{2}$ through: 
$\delta(t)=1-\varphi(t)$. Also the time axys of the curves is adapted so that $\delta(50)=0.50$ (example in Figure S6), to facilitate comparison. The curves are then fitted with the JMAK equation.
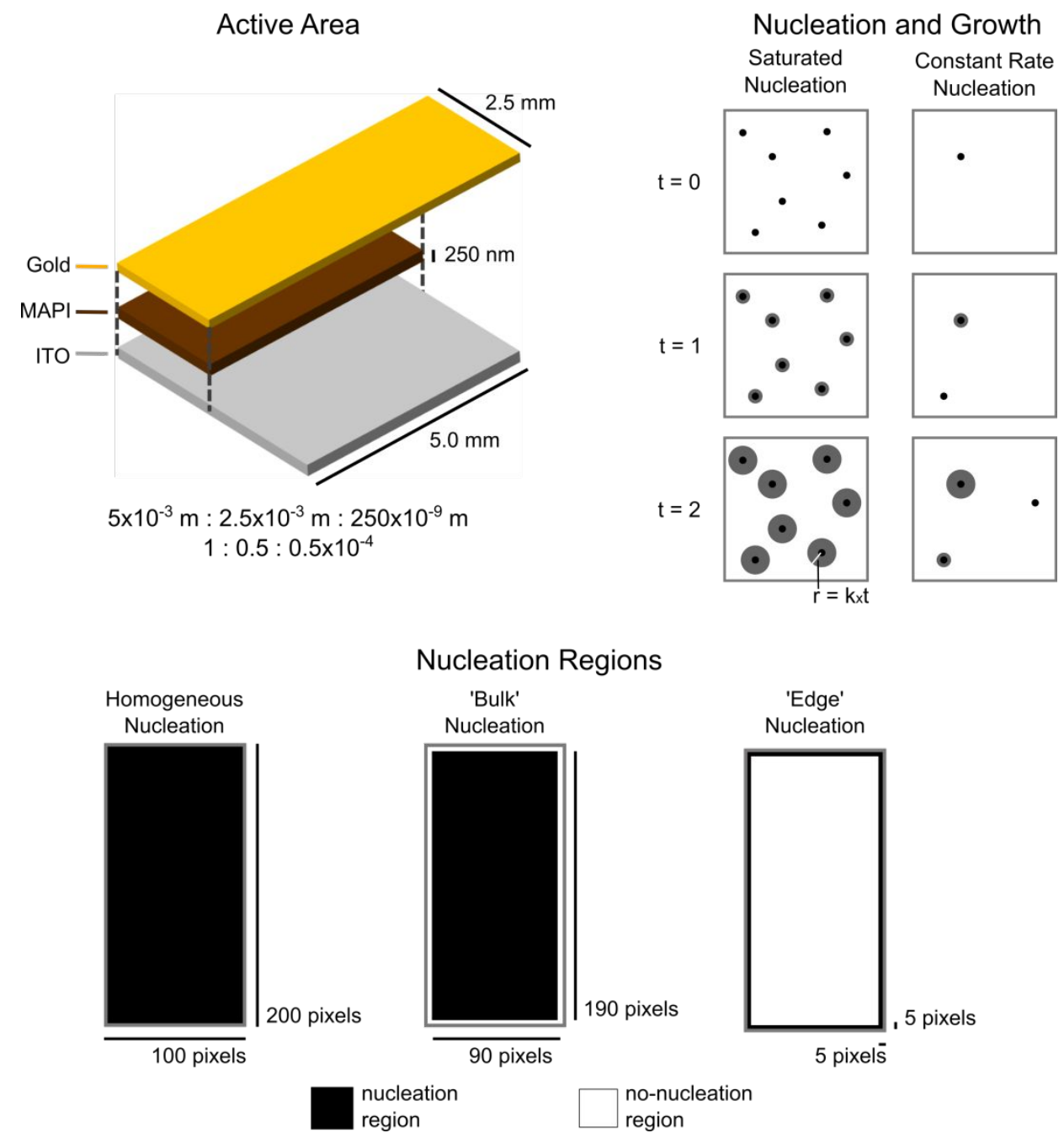

Figure S-6 - Definition of concepts utilized in the simulations: active area, different nucleation and growth conditions and different nucleation regions.

The values of the $\mathrm{n}_{\text {JМAK }}$ extracted from the simulations with constant nucleation rate $\left(2.1 \geq \mathrm{n}_{\text {JMAK }} \geq 2.9\right)$ are much closer to the experimental value $\left(\mathrm{n}_{\text {JMAK }}=3.2\right)$ than the values obtained with saturated nucleation $\left(1.7 \geq \mathrm{n}_{\text {JMAK }} \geq 2.0\right.$, Figure 8a). Moreover, the simulations with constant nucleation rate and with the nucleation limited to the edges of the active area have consistently higher $\mathrm{n}_{\text {JMAK }}\left(2.5 \geq \mathrm{n}_{\text {JMAK }} \geq 2.9\right)$ than simulations of nucleation only in the center $\left(2.2 \geq \mathrm{n}_{\text {JМАK }} \geq 2.7\right)$ or for nucleation without any limitation $\left(2.2 \geq \mathrm{n}_{\text {JМАK }} \geq 2.8\right)$, thus the simulations also indicate that the degradation is driven by edge nucleation. This insight from the simulation is in good agreement with the pictures of the substrates captured during the test. The pictures show the conversion of MAPI into PbI2 first in areas without the gold contact, i.e., outside the active area, and then a progression of the yellow areas into the active area (see Figure S2a). 

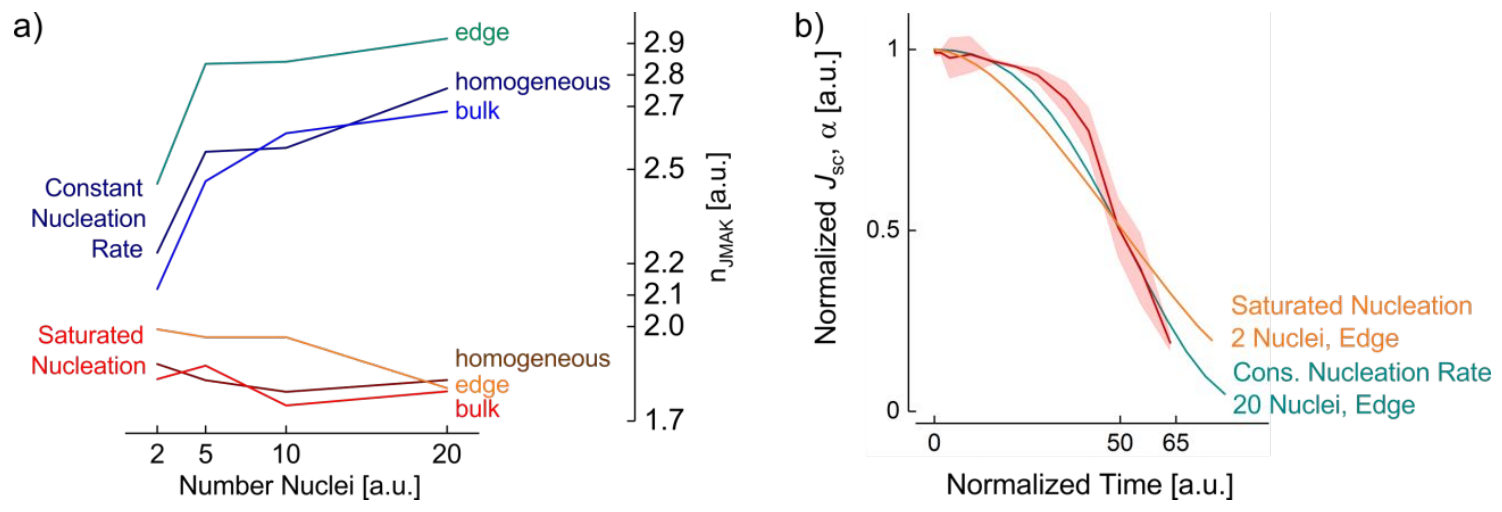

Figure S-7 - Constant nucleation rates produce better description of the degradation of MAPI: a) the $\mathrm{n}_{\text {JMAK }}$ from fitting curves simulated with different nucleation conditions and locations vs number of nuclei; b) best descriptions of the degradation of MAPI with saturated and constant nucleation rate nucleation compared with the measured data at 85 ${ }^{\circ} \mathrm{C}$. 


\section{Voc Reduction}

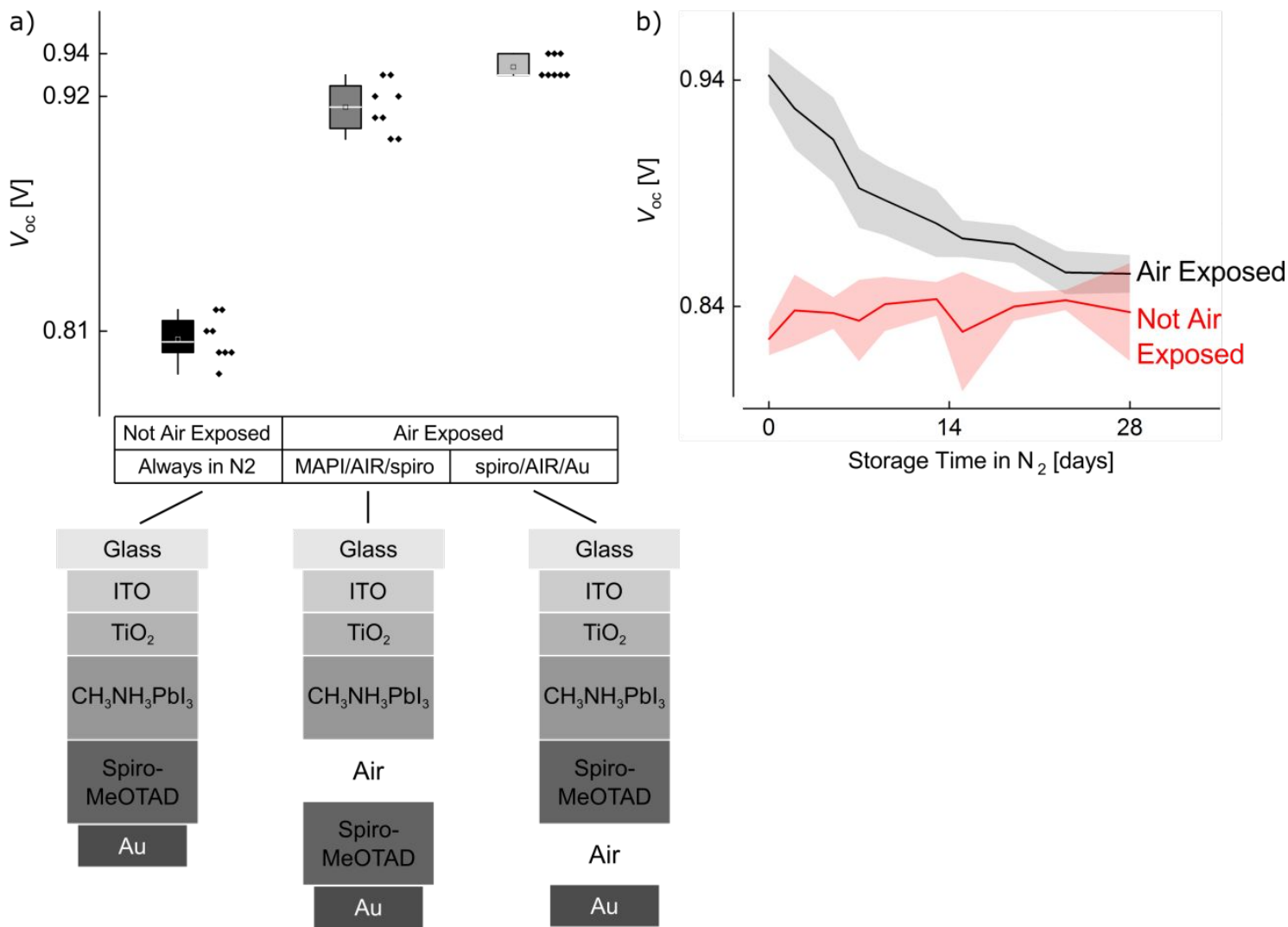

Figure S-8 -Passivation of MAPI by oxygen increases the Voc but is reversible: a) Device that have never been exposed to air have a lower Voc than devices for which the MAPI has been exposed to air; b) over storage time in N2 the Voc of devices that were air exposed decreases to the value of the devices that were never exposed to air. This indicates oxygen desorption from MAPI upon prolonged storage in a N2 atmosphere.
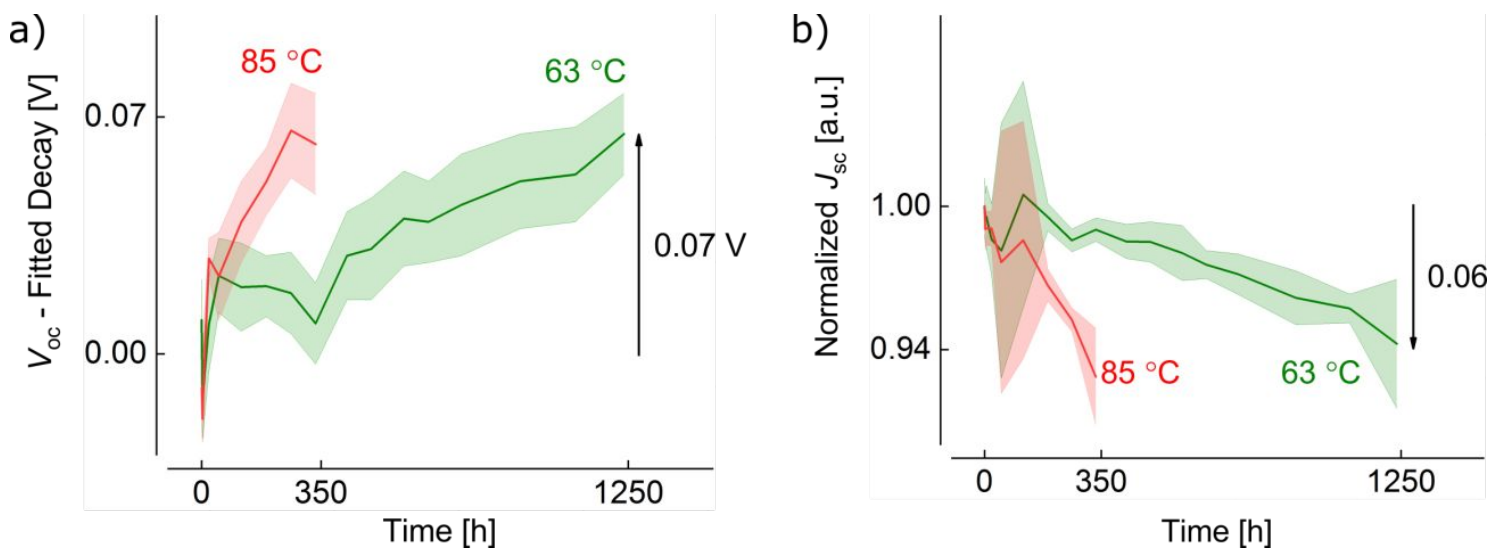

Figure S-9 - Voc gain related to the PbI2 passivation. The increase of $0.07 \mathrm{~V}$ in Voc of the devices stored at $63 \mathrm{C}$ and $85 \mathrm{C}$ happens for the same (a) Jsc loss of $6 \%$ (b) 

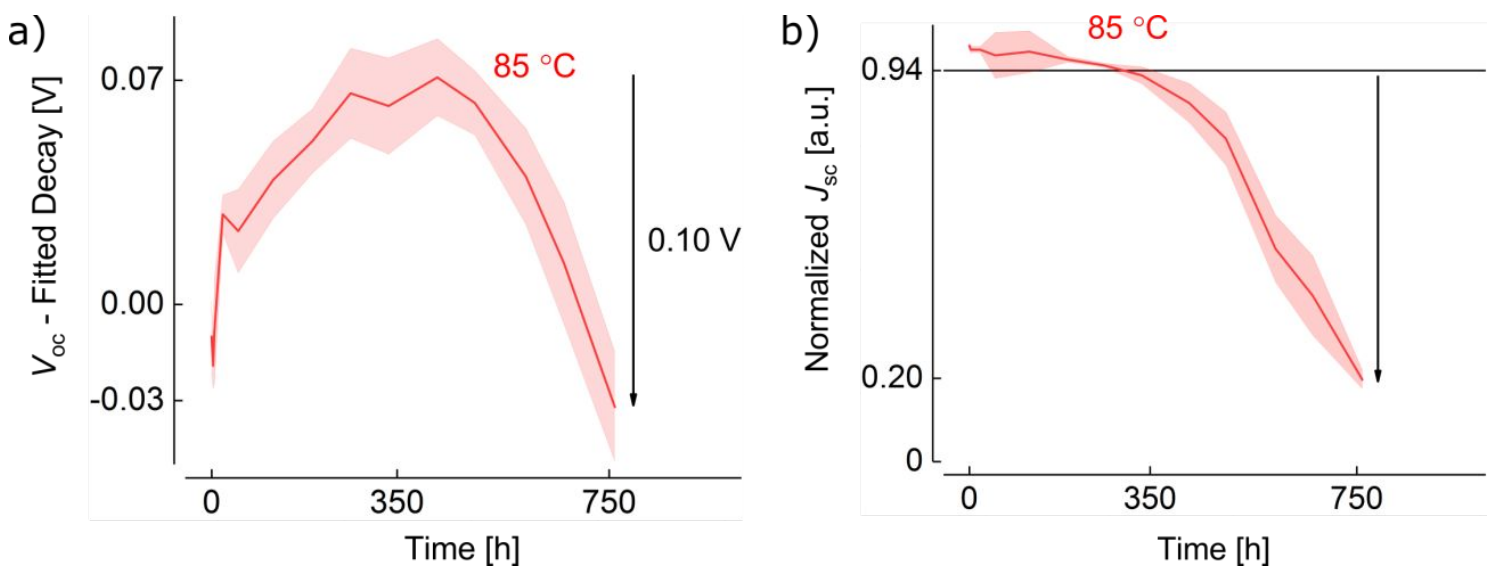

Figure S-10 - Second $V_{o c}$ decay is related to the reduction of $\mathrm{J}_{\mathrm{sc}}$ : a) Second loss of $\mathrm{V}_{\mathrm{oc}}$ for devices stored at $85^{\circ} \mathrm{C}$ after $350 \mathrm{~h}$; b) Corresponding $\mathrm{J}_{\mathrm{sc}}$ reduction. 


\section{FF Reduction}

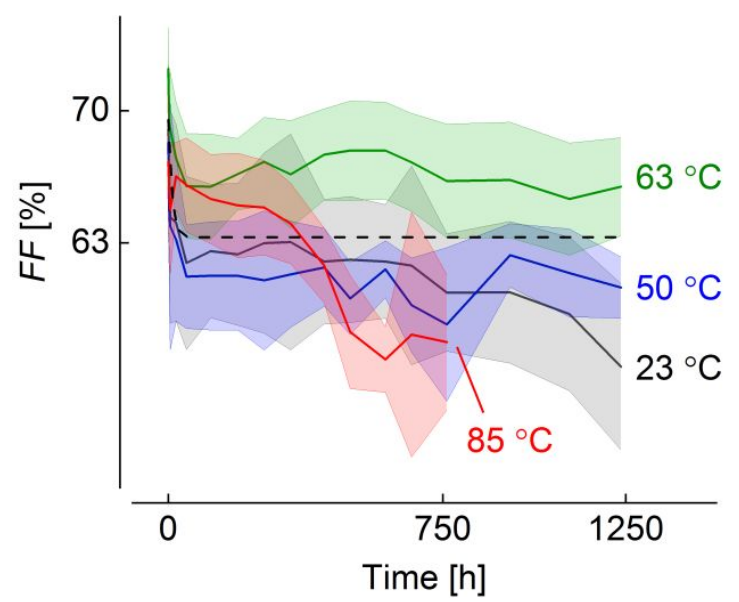

Figure S-11- Progression of the FF of devices held at different temperatures and the equation describing the evolution of the FF in black dashed line.

\section{Derivation of eq. 13}

To simplify the calculations, we assume that the photovoltaic device instantly reaches steady-state. We also assume that the thin device (device area (A) >> device thickness) floats in an infinite non-moving mass of air with fixed temperature $\left(T_{0}\right)$.

In steady state, the power flowing into the device $\left(P_{i n}\right)$ is equal to the power flowing out of the device $\left(P_{\text {out }}\right)$ :

$$
P_{\text {in }}=P_{\text {out }}[W]
$$

Only radiation from the sun $\left(A \cdot p_{\text {sun }}\right.$, with $p_{\text {sun }}$ being the power density from the sun arriving at the device) flows into the device. Electrical $\left(P_{\text {ele }}\right)$ and radiative $\left(P_{\text {rad }}\right)$ power flow out of the device. Convection and conduction are considered to be negligible because the air is assumed to not move, and air has a low thermal conductivity $\left(0.02 \mathrm{~W} \mathrm{~m}^{-1} \mathrm{C}^{-1}\right)$, respectively.

The $P_{\text {ele }}$ generated by a photovoltaic device with a certain power conversion efficiency (PCE) is given by:

$$
P_{\text {ele }}=A \cdot p_{\text {sun }} \cdot P C E[W]
$$

The power radiated by a body at a temperature higher than its surroundings $(T$ in $K)$ is given by the StefanBoltzmann law:

$$
P_{\text {rad }}=\sigma_{B} \cdot A \cdot \varepsilon \cdot\left(T^{4}-T_{0}^{4}\right)[W]
$$

where $\sigma_{\mathrm{B}}$ is the Stefan-Boltzmann constant $\left(5.7 \times 10^{-8} \mathrm{~W} \mathrm{~m}^{-2} \mathrm{~K}^{-4}\right)$ and $\varepsilon$ is the emissivity of the body.

Since there is no direct measurement of $\varepsilon$ for devices similar to ours, we assume $\varepsilon=1$, i.e., that the device is a black body. This assumption is based on the temperatures measured on perovskite devices deployed outdoors ( -20 - $100{ }^{\circ} \mathrm{C}$, according to R. Gehlhaar, et. al., Glob. Challenges 2018, 2, 1800008) that indicate that radiative emission for devices outdoors is dominated by infra-red emission (peak emission for a blackbody at $-20{ }^{\circ} \mathrm{C}$ and $100{ }^{\circ} \mathrm{C}$ are at 11 and $8 \mu \mathrm{m}$, respectively, see figure S12). In this wavelength range, perovskites, the main absorber/emitter material of the device, have practically continuous absorption/emission (C. Müller, et. al., Chem. Mater. 2015, 27, 7835), that 
allows them to be approximated to a black body. Moreover, the device is considered to emit radiation from both sides, so radiative power emission must be doubled. Based on the previous equations we can write:

$$
A \cdot p_{\text {sun }}=A \cdot p_{\text {sun }} \cdot P C E+2 \cdot \sigma_{B} \cdot A \cdot\left(T^{4}-T_{0}^{4}\right)[W]
$$

Rearranging the above equations, we can estimate the device temperature $\left(T_{d e v}\right)$ :

$$
T_{\text {dev }}=\left(T_{0}^{4}+\frac{1-P C E}{2 \cdot \sigma_{B}} \cdot P_{\text {sun }}\right)^{\frac{1}{4}}[K]
$$

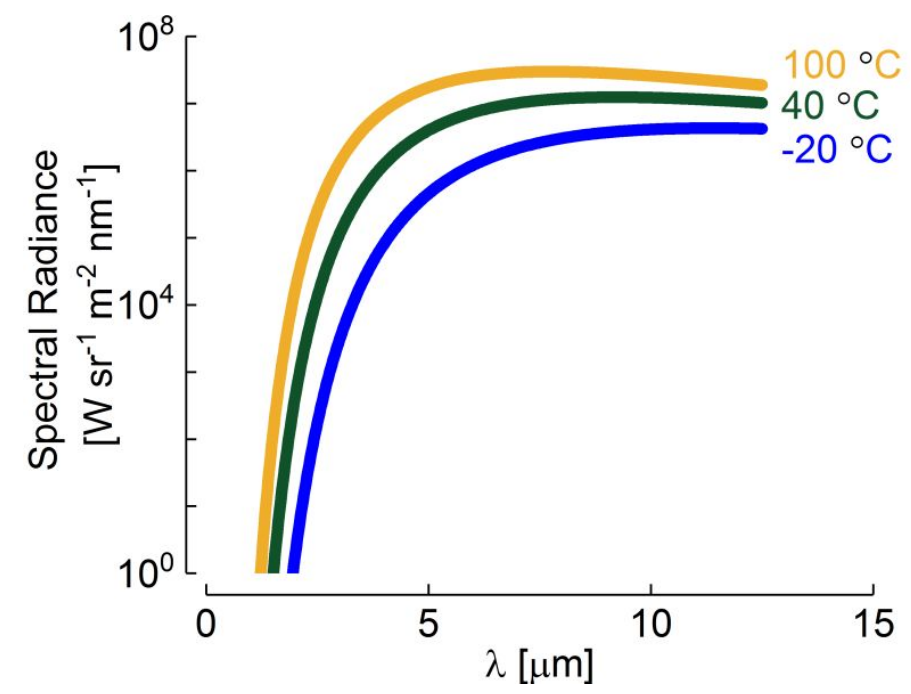

Figure S-12 - Spectral radiance of a black body at different temperatures within the temperature range foreseen for the operation of perovskite photovoltaic outdoors. 